\title{
Los tiempos de la conjugación castellana: vigencia de la propuesta de Bello
}

\author{
Guillermo Soto* \\ Universidad de Chile, Chile
}

\begin{abstract}
Resumen
El presente trabajo analiza la vigencia del análisis de los tiempos verbales del modo indicativo propuesto por Bello (1841), considerando tanto el sistema nuclear como sus extensiones. El sistema de tiempos verbales de Bello constituye un hito fundamental en la gramática del español por su elegancia y su gran adecuación descriptiva. Junto con formular un modelo temporal de admirable perfección, Bello anticipa en sus descripciones problemas que solo podrán ser tratados sistemáticamente con el desarrollo, ya en el siglo $\mathrm{XX}$, de teorías de la aspectualidad, la modalidad y el significado pragmático.
\end{abstract}

Palabras clave: tiempos verbales, sistema verbal, Andrés Bello.

Para correspondencia, dirigirse a: Guillermo Soto Vergara (gsoto@uchile.cl), Universidad de Chile, Facultad de Filosofía y Humanidades, Departamento de Lingüística, Av. Capitán Ignacio Carrera Pinto 1025, Ñuñoa, Santiago, Chile. 


\section{The Spanish tense system: the Persistence of Andrés Bello’s} MODEL

\section{Abstract}

This work analyzes the persistence of the model of the Spanish tenses proposed by Bello (1841), considering both the nuclear system and its extensions, specifically in the indicative mood. The model proposed by Bello is a landmark in the history of Spanish grammar because of its elegance and descriptive adequacy. Bello not only proposed a tense scheme of remarkable perfection, but also dealt with problems that will be systematically studied in the XX century with the development of theories of aspectuality, modality and pragmatic meaning.

Key words: Spanish tenses, Spanish verbal system, Andrés Bello.

Recibido: 29/01/14

Aceptado: 10/03/14

\section{INTRODUCCIÓN ${ }^{1}$}

Ya Amado Alonso, en su espléndida "Introducción a los estudios gramaticales de Andrés Bello" de 1951, destacaba la satisfacción y el orgullo que el filólogo americano sentía por su teoría de los tiempos verbales. En efecto, en el prólogo de su Análisis ideolójica de los tiempos de la conjugación castellana, publicado en 1841 en Valparaíso, Bello afirma, con seguridad, no temer "que, sometida a un examen escrupuloso" su teoría "se halle infundada o inexacta" (Bello 1972 [1841]: 10). Y esto, pues cree "ver en ella, o a lo ménos en sus principios fundamentales, todos los caractéres posibles de verdad y de solidez". Sin falsa modestia, explica que se lisonjea de la preferencia que los lectores dedicados y pacientes darán a su teoría por sobre las de las gramáticas entonces existentes; si bien teme, por el contrario, que los lectores impacientes "se apresuren a condenarla sin haberla entendido". Como ha afirmado Alonso, el orgullo que Bello sentía por el sistema que, según él mismo, había concebido 30 años antes, no era infundado, pues con él resolvía, en los términos de su época, un problema que venía tratándose

\footnotetext{
1 El presente trabajo se desarrolla a partir de lo expuesto en mi tesis doctoral (Soto 2011a) $\mathrm{y}$ ha sido posible gracias al apoyo de los proyectos Fondecyt 1110525 y 1070935.
} 
"desde hacía casi dos siglos" en la bibliografía especializada (Alonso 1951: XLII).

Como es bien sabido, el sistema de tiempos verbales propuesto por Bello (1972[1841], 1951[1847]) ha tenido gran ascendiente en los modelos y descripciones actuales. Si bien Calero Vaquera (2000) discute su influencia en las gramáticas españolas inmediatamente posteriores, planteando que la presencia de categorías semejantes a las del gramático americano obedece a la común influencia de la gramática filosófica francesa, de evidente peso en Bello, resultan válidas hoy las palabras de Guillermo Rojo y Alexandre Veiga (1999), para quienes "[1]a gramática española tiene en este punto, como en tantos otros, el antecedente claro de la visión de las relaciones temporales en el verbo expuesta por Andrés Bello ya en 1841 e incorporada luego a su Gramática" (2876).

Menos divulgados que su sistema de relaciones temporales son, en cambio, algunos de sus esfuerzos por describir aquellos usos de los tiempos verbales que parecen apartarse del sistema propuesto o que presentan propiedades adicionales a este. Como suele plantearse hoy, toda caracterización de los tiempos verbales debe dar cuenta de casos, por así decirlo, anómalos, pero plenamente gramaticales, como el presente histórico, común tanto en las narraciones orales como escritas. Debe, también, hacerse cargo de efectos que puede desencadenar la relación entre tiempos verbales y clases de verbos, como la que se da con los del tipo de conocer, que, como se sabe, modifican su modo de acción cuando incide sobre ellos el pretérito perfecto simple. Bello, junto con proponer una arquitectura temporal de elegante sencillez y gran adecuación descriptiva, se adentra en la maraña de los usos, intentando, en gran parte de los casos, proponer caracterizaciones sistemáticas de lo aparentemente anómalo. En este sentido, junto con ceñirse a los principios racionalistas franceses -en particular los de los gramáticos de Port-Royal, como ha destacado Amado Alonso-, el Bello de los tiempos verbales mantiene su característico apego a los hechos del lenguaje. Podríamos decir que se unen aquí, en una misma tarea, espíritu de geometría y de fineza.

En las páginas que siguen expondré, brevemente, el análisis temporal de Bello, esto es, tanto el sistema nuclear como sus extensiones, en particular en el modo indicativo, destacando, a modo de ilustración, su relación con planteamientos de autores posteriores e intentando, de modo ya más sistemático, una síntesis general de su vigencia. Estoy consciente de que un problema de un trabajo como este puede ser la lectura anacrónica de la obra del gramático americano. Demasiadas veces, los lingüistas -sobre todo, quizás, quienes hemos sido formados en el apego al enfoque sincrónicovemos en tal o cual figura al precursor del enfoque teórico de nuestra preferencia. Esta suerte de búsqueda de ancestros ilustres -tan humana, 
por lo demás- arriesga ocultar la singularidad de la obra, reduciéndola a antecedente de alguna buena nueva lingüística. Aunque he intentado evitar la lectura teleológica, no estoy seguro de haberlo logrado por completo. Con todo, estimo que la tarea de aquilatar la vigencia o el eco que un autor ha seguido teniendo en contextos científicos muy distintos a los existentes cuando su obra se originó, constituye un componente no menor de la práctica académica en una disciplina científica humanista que, como la lingüística, no solo avanza por la formulación de nuevos modelos o la adopción de nuevas tecnologías, sino también gracias a una forma de diálogo con las generaciones anteriores, en especial con sus clásicos.

\section{EL SISTEMA}

El sistema de Bello, aunque no emplee los términos, se funda en la distinción, ya conocida, entre tiempos absolutos y relativos, agregando la posibilidad de tiempos relativos a relativos. Mientras los tiempos absolutos, como el presente, se ubican canónicamente con respecto al momento de habla, los relativos, como el pretérito imperfecto o los compuestos, se localizan en relación con otro tiempo; en otras palabras, los unos se ubican directamente respecto de un centro o eje deíctico temporalmente definido, mientras que los otros se orientan indirectamente ${ }^{2}$. Este es el núcleo de la propuesta de Bello. Los nombres con que denomina los verbos vienen a ser, en el autor, verdaderas definiciones temporales. Si esto es obvio en el caso de los tiempos absolutos (presente, pretérito, futuro), en que cada término explicita la relación de la situación designada respecto del momento de habla, el método es especialmente útil en los relativos, donde el nombre permite reconstruir la relación mediata con dicho momento. Así, por ejemplo, al

2 La distinción entre absolutos y relativos es, siguiendo en esto a Comrie (1985), algo más compleja, pues parece necesario distinguir los meramente relativos, esto es, aquellos que requieren solo la identificación de un punto de referencia en el contexto, con respecto al cual la situación en cuestión puede ser anterior, simultánea o posterior, como ocurre, por ejemplo, con el participio y el gerundio absolutos, de aquellos otros, que Comrie denomina absolutorelativos, que establecen la anterioridad, simultaneidad o posterioridad de una situación respecto de, al menos, un punto de referencia que, a su vez, puede ser pasado, presente o futuro con relación al momento de habla. Aunque, desde esta perspectiva, los tiempos compuestos de Bello son absoluto-relativos, se mantendrá, en el presente trabajo, la tradición de denominarlos relativos. 
leer una denominación como "co-pretérito", referida al modelo cantaba, nos informamos de que el tiempo en cuestión comunica la coexistencia (co) de la situación con otra anterior (pretérito) al momento de habla: Cuando entró, Laura cantaba: el cantar coexiste con el entrar, que es anterior al momento de habla. En la medida en que el sistema permite dos grados de indirección, el modelo habría cantado corresponde a un ante-pos-pretérito, que designa una situación anterior (ante) a otra que es posterior (pos) a una situación anterior (pretérito) al momento de habla. Como escribe en su Gramática, cada una de las denominaciones de Bello "es una breve fórmula, que [...] determina con toda exactitud el significado" (1951[1847]: § 637(a)), en particular, el de las formas compuestas, que se consideran, todas ellas, relativas. De distinto modo, la propuesta temporal de Bello pervive en los modelos posteriores de Bull (1971) y de Rojo (1974) y Rojo y Veiga (1999), que integran, en un paradigma único de base temporal, las formas simples y las compuestas, describiendo los tiempos como puntos orientados directa $\mathrm{o}$ indirectamente al origen, lo que permite distinguir entre orientaciones primarias y secundarias, respectivamente. Como en Bello, en estos modelos el significado temporal resulta de la secuencia de orientaciones que conectan la situación con el punto de origen.

Si bien su sistema sobre el significado fundamental de los tiempos constituye el aporte fundamental de Bello, no pueden dejar de mencionarse sus acotaciones sobre el uso de los tiempos en el discurso y, en particular, su teoría de los significados metafóricos de los tiempos verbales, a que haremos referencia más adelante.

\section{EL SIGNIFICADO DE LOS TIEMPOS VERBALES DEL INDICATIVO}

En el campo del indicativo, Bello reconoce, en primer lugar, el presente, canto, cuyo significado temporal es el de coexistencia del atributo, es decir, de la situación designada, y del momento de habla. El presente no exige que ambos sean coextensivos: basta un momento de coexistencia para que pueda emplearse. De allí, pues, que el predicado pueda haber comenzado mucho antes o continuar mucho después del momento de habla; o bien, pueda tener una duración indefinida o aun ser eterno. De esta caracterización puramente temporal, deriva, pues, el empleo del presente en las cláusulas genéricas; uso que hoy tiende a asociarse, más bien, a propiedades aspectuales del tiempo. 
En lo que respecta al pretérito perfecto simple, canté-llamado "pretérito" por Bello-, este comunica la anterioridad del predicado respecto del momento de habla. El significado temporal específico de las cláusulas en pretérito dependerá, también, del tipo de verbo léxico con que este se combine. Así, si se emplea con verbos desinentes como nacer, esto es, verbos en que la situación, al llegar a su perfección, concluye, el pretérito simple comunica anterioridad de toda la situación con respecto al momento de enunciación. Por el contrario, si se emplea con verbos permanentes como conocer, en que la situación es "desde el principio perfecta" (Bello 1951[1847]: § 625), este pretérito puede -"a veces", escribe Bello- comunicar el comienzo de una situación persistente en el momento de habla. La distinción de Bello reconoce el papel que, en términos actuales, desempeña el modo de acción o aktionsart en la interpretación de las situaciones, categoría que no se incorpora a los estudios gramaticales del español sino hasta más tarde (Rojo 1990). Más precisamente, su planteamiento específico, que, traducido al marco conceptual contemporáneo, es que el significado aspectual del verbo estativo se altera por la incidencia del pretérito, reconoce la existencia de lo que hoy diversos modelos gramaticales y semánticos denominan coerción aspectual endocéntrica: el cambio de tipo implícito en las propiedades aspectuales de una situación léxicamente determinada, típicamente un verbo, que se desencadena por su incompatibilidad con las restricciones o exigencias aspectuales de la unidad gramatical que incide sobre ella (Francis y Michaelis 2003).

Por su significado, que se limita a la ubicación de una situación en el pasado, se ha sostenido que, para Bello, el pretérito es el miembro no marcado del subsistema de pasado (Rallides 1971). Por la misma razón, sería adecuado para informar secuencias de situaciones, lo que tiene importantes efectos en la configuración del discurso narrativo, como se observa más adelante, al tratar el pretérito imperfecto. Como en otros casos, Bello propone aquí explicar temporalmente lo que con posterioridad tenderá a caracterizarse considerando parámetros aspectuales.

Por otro lado, Bello observa también que el pretérito da a entender una idea de negación con respecto al presente: "Decir que una cosa fue es insinuar que no es" (1951 [1847]: § 692). Aunque Criado de Val (1948) considera anecdótico este valor, el gramático español, agudamente, destaca que esta interpretación "más debe atribuirse a un resultado normal del contexto de la frase que a un significado de la forma verbal" (88). En términos más actuales, esto viene a querer decir que el valor atribuido por Bello obedece a una inferencia pragmática del oyente -0 , más bien, a una implicatura del hablante-. La cuestión no es menor, pues apunta, otra vez, a un efecto de sentido que hoy pensamos que deriva de la incidencia de la aspectualidad. 
El futuro simple, cantará, significa, por su parte, que el predicado es posterior al momento de habla. Estos tres tiempos, presente, pretérito y futuro, son absolutos y se determinan considerando solo dos momentos: el del predicado o, en términos actuales, situación, y el de la enunciación o momento de habla. A estos, siguen los tiempos relativos, que suponen al menos tres momentos para la ubicación temporal de la situación.

El co-pretérito, cantaba-correspondiente a nuestro pretérito imperfecto-, comunica, como ya se anticipó, que la situación designada coexiste -nuevamente en el sentido amplio comentado con respecto al presente-con otra situación pasada respecto del momento de habla, como puede ilustrarse en la siguiente oración:

(1) Pedro vio que Juan cortaba el pasto.

En esta, la situación JUAN CORTAR EL PASTO y la situación PEDRO VER ${ }^{3}$ se traslapan temporalmente, tal que el intervalo en que Pedro ve a Juan es un subconjunto del intervalo en que Juan corta el pasto. La definición temporal del co-pretérito sigue vigente en autores posteriores. Ciertamente, en los ya mencionados Bull, Rojo y Veiga, pero también en la Gramáticas académicas de 1920 y 1931, en Coseriu (1996 [1976]), Reichenbach (2005 [1947]) y Carrasco Gutiérrez (1994), que hacen descansar en consideraciones temporales la oposición entre pretérito y co-pretérito. No obstante, desde el siglo pasado, una serie de autores han venido proponiendo, con distintos argumentos, que la oposición entre canté y cantaba descansa en parámetros aspectuales y no puramente temporales, proponiendo que este último es un pretérito imperfecto. Ya Lenz (1935 [1920]) es de esta idea, que han compartido Gili Gaya (1958 [1943]), el Esbozo de 1973, Alarcos (1970 [1949]) y (1994), Hernández Alonso (1996 [1984]) y la Nueva gramática de la RAE (2009). Junto con los argumentos puramente internos a la lengua, la defensa de una oposición aspectual y no temporal se ha visto reforzada por estudios de alcance más general, que han planteado la relevancia en distintas lenguas de la oposición entre perfectivo e imperfecto (así, por ejemplo, Comrie 1985 y Dik 1997).

Una característica de los tiempos relativos de Bello es que no permiten, en términos estrictos, ubicar la situación en cuestión con respecto al momento de habla, una propiedad que la mayor parte de las obras posteriores -entre

Se emplean versalitas para designar la situación que comunica una cláusula, sin considerar las propiedades temporales, de aspecto de punto de vista o los elementos adjuntos (cfr. Smith 1997). 
otros, la Nueva gramática académica del 2009-, con la notable excepción de Reichenbach (2005 [1947]), también han destacado ${ }^{4}$ (Lenz 1935 [1920]; RAE 1920, 1931 y 1973; Gili Gaya 1958 [1943]; Alarcos 1970 y 1994; Coseriu 1996 [1976]; Rojo 1974 y 1990; Rojo y Veiga 1999; Hernández Alonso 1996 [1984]; y, ya con alcance más general, Comrie 1985 y Dik 1997). En el caso del co-pretérito, la descripción de Bello establece dos relaciones temporales: una de coexistencia entre la situación en co-pretérito y una situación pasada, y otra de anterioridad entre la situación pasada y el momento de habla. De estas, no se desprende que la situación en co-pretérito sea necesariamente anterior al momento de habla. Así, por ejemplo, en la oración

(2) Pedro vio que Juan estaba sentado,

es posible que Juan siga sentado en el momento de habla. La determinación específica depende de otros factores y es, finalmente, cuestión de corte pragmático.

Aun cuando, como hemos venido diciendo, y como es esperable, atendido el contexto teórico de su época, el sistema de Bello no atiende al modo de acción, en el caso del co-pretérito sí observa su empleo en situaciones habituales e iterativas, dos categorías de tipo aspectual. Por otro lado, Bello también da cuenta del valor discursivo típico del co-pretérito en la narración: "En las narraciones el co-pretérito pone a la vista los adjuntos y circunstancias, y presenta, por decirlo así, la decoración del drama" (Bello 1951[1847]: § 632).

Esta última observación, unida a su análisis del pretérito, es coincidente con la distinción que, contemporáneamente, se establece entre dos planos de la narración: el primer plano o prominencia y el segundo plano o trasfondo. La distinción -expuesta, entre otros, por Hopper y Thompson (1980) y Reinhart (1984) y de clara utilidad en español (cfr. Soto 2011b)- descansa en la idea de que la narración presenta como condición necesaria un eje temporal constituido por eventos limitados sucesivos, en torno al cual se pueden ordenar otras situaciones. El eje temporal mínimo lo constituye, como han propuesto Labov y Waletzky (1997 [1967]), una secuencia de dos cláusulas temporalmente ordenadas, o cláusulas narrativas, cuyo orden formal replica el orden en que se suceden los eventos en el mundo narrado

\footnotetext{
4 La posición excesivamente localizacionista de Reichenbach ha sido, de hecho, criticada por autores posteriores, lo que ha llevado a una modificación de su modelo de representación que, en la práctica, lo aproxima a la propuesta de Bello (Carrasco Gutiérrez 2008).
} 
y que hace avanzar el punto de referencia temporal que permite ubicar las situaciones designadas. Mientras típicamente el pretérito simple comunica las situaciones del primer plano, el imperfecto comunica las de segundo plano y mantiene el tiempo de referencia heredado -de ahí, como muchos afirman en la actualidad, su carácter temporalmente anafórico-. Notablemente, Bello advierte este empleo discursivo, que hoy -iotra vez!- la bibliografía hace descansar en una oposición aspectual, ahora entre dos aspectos gramaticales: perfectivo e imperfecto (para una presentación en español, véase Soto 2011b)

El pos-pretérito, cantaría, corresponde, por su parte, al condicional simple. Su significado, en el sistema de Bello, es que la situación designada por la cláusula es posterior a otra, pasada respecto del momento de habla. Al igual que en el caso del co-pretérito, el pos-pretérito no ubica la situación designada respecto del momento de habla:

(3) Luisa dijo que volvería a las cinco y así lo hizo efectivamente.

(4) Cristo anunció que volvería al final de los tiempos.

Mientras en (3) la situación en pos-pretérito es anterior al momento de habla, en (4) aún no tiene lugar en este.

En cuanto a las formas compuestas, todas ellas son relativas y aun, en un caso, relativa a relativa, como ya se ha dicho. Aunque la caracterización puramente temporal que propone Bello para estas formas ${ }^{5}$ tiene vigencia en gran parte de la bibliografía posterior (Coseriu 1996 [1976]; Rojo 1990; Rojo y Veiga 1999; Reichenbach 2005 [1947]; Comrie 1985), muchos autores caracterizan estos tiempos apelando a parámetros aspectuales (Lenz 1935 [1920]; RAE 1920, 1931 y 1973; Gili Gaya 1958 [1943]; Alarcos 1970 y 1994; Carrasco Gutiérrez 1994; Hernández Alonso 1996 [1984]; Dik 1997).

El ante-presente, esto es, el pretérito perfecto compuesto, he cantado, designa en Bello una situación que guarda relación con algo que coexiste con el momento de habla. Este planteamiento contrasta con el de gran parte de la bibliografía posterior -entre otros, Lenz (1935 [1920]) y las gramáticas académicas, incluida la de 2009- que ve en el pretérito compuesto una forma absoluta y no relativa, haciendo descansar en parámetros aspectuales o modales su diferencia con el pretérito simple canté. La proposición de Bello, en este punto, presenta un problema evidente, ya observado por Lenz: ¿cómo distinguir en términos estrictamente temporales el pretérito del antepresente si ambos establecen una misma relación temporal de anterioridad al momento

\footnotetext{
Con todo, véase, en lo que sigue, que no siempre la descripción de Bello se ajusta a un parámetro puramente temporal.
} 
de habla? La solución de Bello a la paradoja de proponer una interpretación temporal distinta para los dos tiempos radica, como se desprende de lo ya expuesto, en plantear que el antepresente, a diferencia del pretérito, exige la existencia de una situación específica vigente en el momento de habla. Así caracterizado el tiempo, sin embargo, este no descansa en una relación puramente temporal. Con todo, la idea de que este tiempo vincularía dos situaciones, una de ellas presente, ha seguido, en mayor o menor modo vigente en la bibliografía, incluso en el ya citado Lenz ${ }^{6}$.

Por su parte, el ante-pretérito o pretérito anterior, hube cantado, designa una situación anterior a otra pasada respecto del momento de habla. Siguiendo con el sistema de correspondencias entre nombre y significado temporal, el ante-co-pretérito o pluscuamperfecto, había cantado, debería definirse como el tiempo que designa una situación anterior a otra que coexiste con una situación pasada respecto del momento de habla; es decir, un tiempo relativo a un tiempo relativo. No obstante, Bello introduce aquí un parámetro temporal de distinta naturaleza, que emplea para distinguir ante-pretérito de ante-copretérito: la magnitud del tiempo que media entre la situación designada y la situación pasada respecto de la cual aquella es anterior. Si la anterioridad es inmediata, se trata de ante-pretérito; si no se da esa exigencia, se trata de ante-co-pretérito. Dado que esta dicotomía no se fundamenta en el sistema de relaciones temporales de anterioridad, simultaneidad y posterioridad que sustenta al resto de los significados temporales, constituye una anomalía en el modelo de Bello. De hecho, apelando a esta anomalía, Rojo y Veiga (1999) proponen eliminar hube cantado del paradigma.

Por otro lado, el ante-futuro o futuro compuesto, habré cantado, designa una situación anterior a otra posterior al momento de habla, como en el ejemplo de Bello:

(5) Procura verme pasados algunos días: quizá te habré buscado acomodo (1951[1847]: § 645).

De modo análogo a lo que ocurre en los otros tiempos relativos, Bello observa que la situación designada por el participio no se ubica necesariamente en el futuro, aunque esta posición temporal sea la típica: lo imprescindible "es la idea de anterioridad a un futuro". El siguiente ejemplo, dado por el autor, ilustra la indefinición temporal de la situación designada:

6 En nuestra tesis doctoral (Soto 2011a) operamos sobre esta misma idea, aprovechando la formalización propuesta por Nishiyama y Koenig (2010). 
Una persona que ha salido de su patria largo tiempo ha, y que no espera volver a ella en algunos años, podrá decir muy bien: "Cuando vuelva a mi país, habrá cambiado sin duda el orden de cosas que allí dejé”; y podría decirlo ignorando completamente si al tiempo que lo dice está todavía por verificarse el cambio (Bello 1951[1847]: § 645).

Por su parte, el condicional compuesto, o ante-pos-pretérito, se define, como ya hemos dicho, por la relación de anterioridad entre la situación designada por el participio y otra situación que es, a su vez, posterior a una tercera situación anterior al momento de habla (Bello 1951[1847]: § 648). Así, en el ejemplo de Bello

(6) Díjome que procurase verle pasados algunos días; que quizá me habría hallado acomodo,

hallar es anterior a procurar; mientras que procurar es posterior a decir, que es, a su vez, anterior al momento de habla.

Un aspecto notable de la teoría de Bello -en que esta parece descriptivamente superior aun a teorías temporales de gran rigor como la de Reichenbach (2005 [1947])- radica en su reconocimiento de que, en el caso del ante-pos-pretérito, se requiere de cuatro momentos temporales para ubicar adecuadamente la situación de que se habla (Carrasco Gutiérrez 2000).

Al igual que en los otros tiempos relativos, la descripción de Bello no permite una ubicación de todos los momentos temporales implicados en el ante-pos-pretérito en una única línea temporal. En el ejemplo del gramático, se especifican tanto el orden decir $>$ hallar $>$ procurar como el orden decir $>$ momento de habla; no se precisa, sin embargo, la relación que la secuencia hallar > procurar tiene con el momento de habla. Carrasco Gutiérrez (2000) ha tratado esta propiedad de las descripciones de los tiempos relativos en Bello, indicando que corresponde a situaciones de vaguedad y no de ambigüedad. Estando de acuerdo con su análisis, solo agregamos que esta vaguedad no responde a una deficiencia de la descripción gramatical sino que es propia de la forma verbal. De hecho, esta vaguedad es un argumento para sostener que una adecuada interpretación del modelo de Bello debe entender este como un sistema no de ubicación de los tiempos, sino de orientación, en el sentido de la propuesta de Rojo (1974) y Rojo y Veiga (1999). 


\section{LOS SIGNIFICADOS TRASLATICIOS}

A partir del significado básico de los tiempos, Bello identifica también, más allá de los valores de uso recién indicados, significados secundarios y metafóricos, destacando, en ambos casos, el carácter sistemático de las traslaciones semánticas; en otras palabras, que el desplazamiento temporal que acompaña a los significados traslaticios no afecta solo a la situación específica, sino a la serie de relaciones temporales que esta establece respecto del momento de habla. Ello explica que tales movimientos operen con frecuencia en el nivel transoracional de los períodos o secuencias discursivas.

En lo que respecta a los significados secundarios del indicativo, antecedidas por $s i$, las formas que significan coexistencia (presente, pretérito imperfecto o co-pretérito, pretérito perfecto compuesto o ante-presente y pluscuamperfecto o ante-co-pretérito) se emplean con valor de subjuntivo hipotético, desplazándose una posición hacia el futuro en el sistema, tal que el presente pasa a futuro y las formas co- a pos-:

(7) Si canto, te dedicaré la canción (Bello 1951 [1847]: § 670).

En el caso de las formas compuestas, el ante-presente puede, en este contexto, significar ante-futuro, como en el ejemplo de Bello:

(8) Si para fines de la semana ha venido del campo nuestro amigo, le hospedaremos en casa (1951 [1847], § 664).

En el ejemplo, indica el autor, el ante-presente es equivalente a hubiere venido. Un desplazamiento temporal análogo ocurre, en el mismo contexto, con el ante-co-pretérito, que asume valor de ante-pos-pretérito, como se desprende del siguiente ejemplo:

(9) Prevínole que cuando viese que en alguna batalla le habían partido por medio del cuerpo.

En la primera, el ante-presente toma valor de ante-futuro; mientras que en la segunda, el ante-co-pretérito asume el valor del ante-pos-pretérito.

Otro desplazamiento recogido por Bello es aquel en que el futuro y el ante-futuro cubren el campo del imperativo, comunicando una orden que no puede dejarse de cumplir:

(10) Me habréis aderezado la comida (Bello 1951 [1847]: § 683). 
Nótese, sin embargo, que en este caso el significado temporal fundamental sigue presente en la forma compuesta, lo que ha cambiado es, más bien, la modalidad, que pasa a deóntica.

Si el tratamiento de los significados secundarios es sistemático, la determinación de los metafóricos descansa, además, sobre una teoría general de la mente humana que incluye al lenguaje. Bello fundamenta el uso metafórico a partir de la vinculación entre el uso recto de los tiempos verbales con determinadas facultades mentales, a saber, percepción, memoria y raciocinio. Estas facultades proyectan a la representación mental de la situación designada ciertos rasgos fenoménicos o experienciales característicos. Así, el presente, al asociarse con la percepción actual de los fenómenos, se vincula con representaciones mentales más vivas; los pretéritos, por su parte, se asocian con representaciones menos vívidas, conectadas con la memoria y caracterizadas por la visión distante y "como entre sombras" (1951 [1847]: § 685) de lo pasado; los tiempos futuros, finalmente, también producen representaciones menos vivas, ligadas esta vez "al raciocinio, que vislumbra dudosamente el porvenir". En otras palabras, los tiempos verbales de cada espacio temporal básico (coexistencia, anterioridad y posterioridad) poseen cierta fuerza imaginística que, en términos contemporáneos, podríamos plantear que deriva del modo de acceso epistémico a la situación designada.

Esta fundamentación cognitiva de los tiempos sirve de base para traslaciones de acuerdo con las cuales una forma dada, conservando su fuerza imaginística, pierde su valor temporal fundamental y pasa a asumir el significado temporal propio de otra, añadiéndole su fuerza. De ahí, pues, el carácter metafórico del proceso. Así, por ejemplo, el empleo del presente en el campo de la anterioridad -el denominado presente histórico-produce una expresión más vívida de los recuerdos y da más animación y energía a las narraciones; mientras que la sustitución del presente o el pretérito por el futuro permite comunicar la consecuencia lógica, la probabilidad o la conjetura, como en expresiones del tipo

(11) Estará enfermo.

(12) Serán las cinco de la tarde.

La traslación no opera, por tanto, aisladamente para cada tiempo, sino que está sujeta a un sistema que, a su vez, se fundamenta extragramaticalmente, en el sistema perceptivo y cognoscitivo humano.

Los principios se aplican también a las formas compuestas, por lo que, por ejemplo, el ante-presente puede reemplazar al ante-co-pretérito en el contexto de una traslación general desde la anterioridad a la coexistencia, 
que puede darse en el discurso narrativo con el objeto de dar "más viveza a los recuerdos" y "más animación y energía" a los relatos (1951 [1847]: § 686). Del mismo modo, el ante-pos-pretérito puede sustituir al co-pretérito para comunicar una "presunción verosímil" en una oración como la siguiente:

(13) Todavía se descubría en sus facciones que en su mocedad habría hecho puntear a sus rejas bastantes guitarras (Bello 1951 [1847], § 689).

$\mathrm{O}$ el futuro por el presente y el ante-futuro por el ante-pretérito, respectivamente, para significar "mera probabilidad", como en

(14) Cara más hipócrita no la habrás visto en tu vida.

En estos últimos casos, la forma futura desplazada asume un significado modal epistémico subjetivo (cfr. Dik 1997).

Al igual que en el caso de los significados secundarios, la traslación, aunque opere en un texto particular, lo hace sistemáticamente, conllevando cambios análogos en los otros tiempos, como explica nuestro autor en la siguiente cita:

\begin{abstract}
"Al echar de ver que su fementido amante se había hecho a la vela, y la había dejado sola y desamparada en aquella playa desierta, no pudo la infeliz reprimir su dolor". Dígase se ha hecho, la ha dejado, no puede, y la narración tomará otro color (Bello 1951 [1847]: § 686).
\end{abstract}

Vista desde la óptica del presente, la propuesta bellista viene a reconocer que en estos significados traslaticios los tiempos verbales pasan a emplearse para comunicar otra cosa, que hoy llamamos modalidad. En particular, sus aproximaciones a la modalidad epistémica resultan especialmente penetrantes y sugieren una motivación extralingüística para la común asociación que se observa entre esta y el tiempo futuro (Lyons 1977).

\title{
5. CONCLUSIÓN
}

Como se desprende de lo hasta aquí expuesto, Bello sienta las bases para una caracterización deíctica de los tiempos verbales que considera tanto los absolutos como los relativos y que da cuenta tanto de los significados temporales básicos como de significados secundarios o extendidos. Aunque, como observa Alonso (1951), su modelo temporal descansa en propuestas anteriores, Bello no solo aplica al español un esquema preexistente, sino 
que lo modifica, incorporando nociones que incrementan su adecuación descriptiva, como se ha observado respecto de su análisis del ante-pospretérito. La vigencia de la propuesta bellista se da, ante todo, en la línea desarrollada por Guillermo Rojo y continuada, también, por Alexandre Veiga (Rojo 1974; Rojo y Veiga 1999). De hecho, innovaciones que estos autores incorporan-como la idea de que los tiempos no se establecen a partir, estrictamente hablando, de un punto de origen correspondiente al momento de habla o, siguiendo en esto a Bull (1971), que los tiempos orientan y no localizan temporalmente-, se relacionan evidentemente con el análisis de Bello. En efecto, en particular respecto de los tiempos relativos, Bello es, como hemos visto, claro en que estos no localizan respecto del momento de habla. En términos actuales, podríamos decir que la descripción puramente temporal de los tiempos verbales subdetermina la ubicación temporal de las situaciones designadas, particularmente en el caso de los tiempos relativos, la que demanda, para su concreción, la consideración de factores pragmáticos. Por otro lado, en su análisis de los significados traslaticios, Bello propone, como vimos, desplazamientos que afectan no solo a un tiempo particular, sino al sistema completo que describe la orientación temporal del verbo. El carácter sistemático de estas traslaciones sugiere la posibilidad, actualizada por Rojo, de generalizar el modelo temporal, eliminando la restricción según la cual el punto de origen debe corresponder al momento de habla. Esta generalización, que libera al modelo de un anclaje referencialista directo, permite tratar bajo un mismo principio los significados básicos y secundarios de Bello.

No obstante la sistematicidad con que opera en esta materia el gramático americano, la tensión entre el teórico y el descriptivista le lleva a relajar, en algunos puntos, la aplicación pura del modelo y a intentar dar cuenta de significados que no parecen explicarse apelando solo a criterios temporales. Esto es claro, como se ha visto, en la descripción del ante-presente y, sobre todo, en la oposición propuesta entre ante-pretérito y ante-co-pretérito. $\mathrm{Si}$ bien la paradoja que genera la primera descripción puede resolverse, en un modelo temporal, gracias a las noción de vector de Bull (1971) y de Rojo (1974), y a la generación recursiva de secuencias de anterioridad, simultaneidad y posterioridad respecto del punto de origen, propuesta por Rojo (1974) -o, en su defecto, a la idea de perspectiva secundaria de Coseriu (1996 [1976])-, el problema que se advierte en la oposición entre habia cantado y hube cantado no parece encontrar solución en un modelo puramente temporal.

En distintos pasajes, se observa en Bello la conciencia de que influyen en el significado de los tiempos verbales factores que hoy integramos bajo el ámbito de la aspectualidad, como se observa cuando describe algunos 
significados del imperfecto dependientes del tipo de verbo o como sucede, notablemente, en su precisa caracterización del cambio de significado que sufren ciertos verbos permanentes en pretérito. Con todo, es claro que Bello no podía hacer uso sistemáticamente de una categoría, la aspectualidad, que no se había desarrollado aún en los estudios semánticos y gramaticales. Si bien se advierten, como hemos visto, consideraciones relativas, aunque no sistemáticas, a la noción actual de modo de acción o aktionsart, la ausencia del aspecto de punto de vista o gramatical es clara en su obra. De hecho, una de las diferencias más notorias entre el sistema de Bello y gran parte de las caracterizaciones actuales de los tiempos verbales radica en el papel que desempeñan tanto el aspecto léxico como el gramatical. El incremento de consideraciones aspectuales en las descripciones gramaticales de los tiempos verbales del español puede observarse no solo contrastando a Bello con autores posteriores, sino también cotejando las propias gramáticas de la academia. En efecto, quizás el aspecto más sobresaliente en que la Nueva gramática del 2009 se aparta del Esbozo y de las gramáticas anteriores está en el fuerte papel que se asigna en ella a los distintos aspectos. Con todo, persisten en la bibliografía, como hemos visto, los modelos puramente temporales. En particular, la corriente de Rojo intenta, aún hoy, reducir a categorías temporales lo que otros describen aspectualmente, bajo el supuesto de que el aspecto gramatical es una categoría secundaria en español (cfr. Coseriu 1996 [1976]).

También se observan en Bello intentos de resolver, en el marco conceptual de su época, cuestiones que hoy integraríamos en el campo de la modalidad. Notable resulta, en este sentido, su conciencia de que los desplazamientos temporales generan ciertos efectos de sentido no reducibles a la esfera temporal. En particular, su teoría de los significados metafóricos propone una fundamentación cognitiva de dichos efectos, asumiendo una visión integrada entre el lenguaje y el resto de las facultades mentales. No obstante, también es claro aquí, como en el caso de la aspectualidad, que Bello no podía aplicar sistemáticamente categorías semánticas y gramaticales que no estaban disponibles. Algo similar ocurre con sus observaciones sobre usos que hoy caracterizaríamos pragmáticamente y que en Bello son descritos de modo ateórico.

El sistema de tiempos verbales de Bello constituye un hito fundamental en la gramática del español, cuya vigencia descansa en su elegancia y su gran adecuación descriptiva. Junto con proponer un modelo temporal de admirable perfección, Bello anticipa en sus descripciones problemas que solo podrán ser tratados sistemáticamente con el desarrollo, ya en el siglo XX, de teorías de la aspectualidad, la modalidad y el significado pragmático. Más allá de estas innovaciones, aún hoy las investigaciones sobre los tiempos 


\section{verbales del español se interpretan contra el fondo conceptual desarrollado por el gramático americano.}

\section{REFERENCIAS BIBLIOGRÁFICAS}

Alarcos Llorach, Emilio. 1970 [1949]. Sobre la estructura del verbo español moderno. En Estudios de gramática funcional del español, pp. 50-89. Madrid: Gredos. - 1994. Gramática de la lengua española. Madrid, Espasa-Calpe.

Alonso, Amado. 1951. Introducción a los estudios gramaticales de Andrés Bello. Prólogo a Andrés Bello, Gramática de la lengua castellana destinada al uso de los americanos, Obras completas de Don Andrés Bello, Vol. IV, p. ix-lxxxvi. Caracas: Ministerio de Educación.

Bello, Andrés. 1951 [1847]. Gramática de la lengua castellana destinada al uso de los americanos. En Obras completas de Don Andrés Bello, Vol. IV. Caracas: Ministerio de Educación.

1972 [1841]. Análisis ideológica de los tiempos de la conjugación castellana. Reproducción facsimilar de la edición príncipe. Caracas: Gobernación del Distrito Federal.

Bull, William. 1971. Time, tense and the verb, a study in theoretical and applied linguistics, with particular attention to Spanish. Berkeley: University of California Press.

Calero Vaquera, María Luisa. 2000. La recepción de Bello en las gramáticas españolas del XIX. En Christian Schmitt y Nelson Cartagena (coords.). La gramática de Andrés Bello (1847-1997). Actas del congreso-homenaje celebrado con motivo del ciento cincuenta aniversario de la Gramática de la lengua castellana destinada al uso de los americanos, pp. 1-20. Bonn: Romanisticher.

Carrasco Gutiérrez, Ángeles. 1994. Reichenbach y los tiempos verbales del español. Dicenda: Cuadernos de filología hispánica 12: 69-86.

2000. Los sistemas temporales de Andrés Bello y Hans Reichenbach. En Christian Schmitt y Nelson Cartagena (coords.). La gramática de Andrés Bello (1847-1997). Actas del congreso-homenaje celebrado con motivo del ciento cincuenta aniversario de la Gramática de la lengua castellana destinada al uso de los americanos, pp. 319-347. Bonn: Romanisticher.

2008. Los tiempos compuestos del español: formación, interpretación y sintaxis. En Ángeles Carrasco Gutiérrez (ed.). Tiempos compuestos y formas verbales complejas, pp. 13-64. Madrid: Iberoamericana-Vervuert.

Comrie, Bernard. 1985. Tense. Cambridge: Cambridge University Press.

Coseriu, Eugenio, 1996 [1976]. El sistema verbal románico. México, D. F.: Siglo XXI [Traducción del original en alemán Das romanische Verbalsystem. Tübingen: Gunter Narr, 1976].

Criado de Val, Manuel. 1948. Sintaxis del verbo español moderno. I. Metodología. II. Los tiempos pasados del indicativo. Madrid: Anejos de la Revista de Filología Española.

Diк, Simon C. 1997. The Theory of Functional Grammar. Part 1: The Structure of the Clause. Ed. K. Hengeveld. Berlin/New York: Mouton de Gruyter.

Francis, Elaine y Laura Michaelis. 2003. Mismatch: a crucible for linguistic theory. En Elaine Francis y Laura Michaelis (eds.). Mismatch: form-function incongruity and the architecture of grammar, pp. 1-27. Stanford: CSLI Publications. 
Gili Gaya, Samuel. 1958 [1943]. Curso superior de sintaxis española. 9. ${ }^{a}$ ed. Barcelona: Bibliograf.

Hernández Alonso, César. 1996 [1984]. Gramática funcional del español. 3. ${ }^{\text {a }}$ ed. Madrid: Gredos.

Hopper, Paul y Sandra Thompson. 1980. Transitivity in grammar and discourse. Language 56(2): 251-299.

Labov, William y Joshua Waletzky. 1997 [1967]. Narrative analysis. Oral versions of personal experience. En Michael G. W. Bamberg (ed.), Oral versions of personal experience: three decades of narrative analysis, Vol. 7, pp. 3-38. Mahwah: Lawrence Erlbaum [Edición original en June Helm (ed.), Essays on the verbal and visual arts. Proceedings of the 1996 Annual Spring Meeting of the American Ethnological Society, pp. 12-44. Seattle: University of Washington Press].

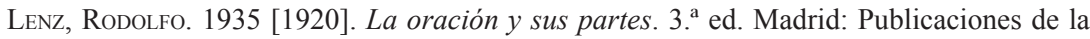
Revista de Filología Española.

Lyons, John. 1977. Semantics, Vol. 2. London: Cambridge University Press.

Nishiyama, Atsuko y Jean-Pierre Koenig. 2010. What is a perfect state. Language 86(3): 611-646.

RAE (Real Academia Española). 1920. Gramática de la lengua española. Madrid: Sucesores de Hernando. 1931. Gramática de la lengua española. Madrid: Espasa-Calpe.

- 1973. Esbozo de una nueva gramática de la lengua española. Madrid: EspasaCalpe.

2009. Nueva gramática de la lengua española, Madrid: Espasa.

RALlides, Charles. 1971. The tense aspect system of the Spanish verb, as used in cultivated Bogotá Spanish. La Haya: Mouton.

Reichendach, Hans. 2005 [1947]. The tenses of verbs. En Inderjeet Mani, James Pustejovsky y Rob Gaizauskas (eds.). The language of time: a reader, pp. 71-78. Oxford: Oxford University Press. [Edición original en Hans Reichenbach. 1947. Symbolic logic. New York: MacMillan].

Reinhart, TANYA. 1984. Principles of gestalt perception in the temporal organization of narrative texts. Linguistics 22: 779-809.

Rojo, Guillermo. 1974. La temporalidad verbal en español. Verba 1: 17-43.

1990. Relaciones entre temporalidad y aspecto en el verbo español. En Ignacio Bosque (ed.). Tiempo y aspecto en español, pp. 17-43. Madrid: Cátedra.

Rojo, Guillermo y Alexandre Veiga. 1999. El tiempo verbal. Los tiempos simples. En Ignacio Bosque y Violeta Demonte (dirs.). Gramática descriptiva de la lengua española, Vol. 2, pp. 2867-2934. Madrid: Espasa Calpe / Real Academia Española, Colección Nebrija y Bello.

Smith, CARlota. 1997. The parameter of aspect. $2 .^{a}$ ed [1. ${ }^{a}$ ed.: 1991]. Dordrecht: Kluwer.

Soto, Guillermo. 2011a. Los tiempos compuestos en el español de América. Tiempo, aspecto y uso. Tesis doctoral, Universidad de Valladolid.

2011b. Estructura narrativa y proyecciones entre situaciones homogéneas y discretas: léxico, gramática y coerción. Lenguas Modernas 37: 109-125. 